\title{
COMMENTARY
}

\section{On classic and modern ethical issues in business and management academic research}

\author{
Wei Hong $^{1^{*}}$ Hong Mei Yu ${ }^{1}$ \\ ${ }^{1}$ Faculty of Business, City University of Macao, Macao 999078, China
}

\section{Check for updates}

Correspondence to: Wei Hong, Faculty of Business, City University of Macao, Macao 999078, China; E-mail: popllkk45@yahoo.co.uk

Received: September 29, 2021;

Accepted: November 8, 2021;

Published: November 16, 2021.

Citation: Hong W and Yu HM. On classic and modern ethical issues in business and management academic research. Front Manage Bus, 2021, 2(1): 118125. https://doi.org/10.25082/FMB.2021.01.006

Copyright: () 2021 Wei Hong \& Hong Mei Yu. This is an open access article distributed under the terms of the Creative Commons Attribution License, which permits unrestricted use, distribution, and reproduction in any medium, provided the original author and source are credited.

\section{(\$)}

\begin{abstract}
Ethical issues are critical to researchers, and this has been a hot topic in decades. Many classic ethical issues, such as plagiarism and fabrication, are repetitively discussed, but some contemporary ethical issues are still problematic and overlooked for researchers, especially those young scholars. The purpose of this paper is to analyse and discuss ethical issues around contemporary business and management academic studies. This paper found that first, scholars are internally and externally pushed to produce rigorous theory development papers, neglecting the relevance of practice. Second, researchers devoted themselves in improving their academy degree or meeting requirements from their employers instead of dealing with practical problems and their interests in research. Third, some 'self-plagiarism' behaviours, such as segmented publication, are arguable in the academy study, which leads to a waste of publication, but it is hard to discern and needs to be tackled.
\end{abstract}

Keywords: ethic issues, self-plagiarism, rigour and relevance

\section{Introduction}

Research ethical issues are a common topic in the academic realm, and many scholars are first taught to be academicians who are integral, honest, upright, careful, and persistent. In this sense, scholars should be free from bias, conflicts of interest, and other factors that affect the scientific process. However, in the face of external pressures, $15.5 \%$ of scientists change the design, methodology, and/or results of a study coping with financial pressures from funds, while $12.5 \%$ of them are neglected to other flawed data and problems in research [1].

Despite subjective intentions towards ethic misconducts among scientific researchers, organisations or institutions also play a pivotal role in moderating scientists' perceptions of academic integrity because of institutional unfairness [2], rigid performance management towards academic publications [3,4], and political agenda [1].

In this regard, this paper discusses ethical issues around contemporary business and management studies, but instead of discussing conventional ethical issues, i.e., plagiarism, this paper mainly looks at three ethical issues related to management science, including the (a) the dilemma of practical relevance and theoretical development, (b) conflicts between research rigour and relevance, and (c) some arguable 'self-plagiarism' actions. Therefore, it may not be properly called ethical problems from scholars, but it may be labelled as problems from business and management academical studies. We argue these misconducts may severely undermine management science regarding future studies and development.

\section{Management research dilemma, between relevance and theory development}

Modern management study emerged in the 1950s, and is closely linked to industry and business development, however, with many years of development and evolvement, it is still arguable whether management studies should be claimed as 'science'. Those leading universities, i.e., Cambridge University, which were reluctant to set up the business school, have to face mounting pressures from successful business schools in those young universities, i.e. Warwick University; consequently, they surrendered to external pressure and opened the business school to teach people "skills of making money, though they would see it as 'skills' instead of 'knowledge or science"” [5]. 
The debate on relevance and theory development continues, and it will never cease. Bai (2020) [6] argued, in Research Studies Redirecting Practice-Oriented, that management theory should closely connect with management practices. Qi et al. (2010) [7] argued, in the initiative The Forecast: Facing the Chinese Management Practice, that academic studies should serve the practices, since without the practices, management theories are of no use.

To connect the theory with the practice, the priority is to clarify the relationship between business academic research and practices. Bai (2020) [6] asserted that management practices are the fundamentals of management theories development, which implies that the theory development should be meaningful for the management practice. In other words, management theories should be beneficial for management practitioners. Jia and Kong (2020) [8], reviewed the papers in an academy management forum, found that China management theory development still faces pressures in connecting theory development with real practice, and abundant research works are lack of practice value. As Qi (2012) [9] stated, it exists in China that a dual system where management theories growth and management practices development are separated Which is to say that management theories cannot effectively guide management practices. Though some management researchers claimed the plausibility of existing two paralleling systems is derived from the different languages used in academy and practice, this separation is critiqued as the value of management theories and theoretical development are depreciated since the difficulty in application [9].

Presumably, the derail of academy studies and business practices is rooted in the scarcity of theoretical breakthrough. It could be interpreted from two dimensions: first, it cannot explain phenomena. From management theory application perspective, the Taylorism and standardisation of management empirically promote productivities. Tourish (2019) [10] pointed out that Taylor's science of management greatly boosts the productivities of manufacturing and contributes to manpower release. However, entering into 5G, AI, Blockchain, IoT era, the current management theories related to firm or business management are improper and hard to explain these advancements. Actually, management theories are too far from these technology fields.

From a management development point of view, it is of tremendous difficulties to make breakthroughs and to interpret complex and correlated management issues. For instance, outdated leadership theories were critiqued for its continuing application [11,12], while the gap between theory building and theory application has been widening [13]. The changing environment and upgrading technology worked together, continually challenge the theories. As Latham (2014) [12] urged, it is evident that the need of upgrading and integrating leadership academic research, whereas scholars need to step out of their comfort zone to integrate with existing theories and evolve theories to solve practical issues in the real world.

From management research inertia perspective, subject to the contemporary business world, vertical and horizontal business integrations incessantly challenge theories development in business and management. Professor Zhang Jin Long, in his report Thinking of China practice management studies, pointed out that the innovations and creativities made by Chinese enterprises should be studied by Chinese management scholars, where more interpretations and in-depth research are needed, therefore subject to rapid changing environment, management theory should be reconstructed, and more studies from multiple dimensions and perspectives are needed [8]. Scholars may fall into dead-end, because it is obviously difficult to overthrow a well-established rigorous research paradigm and tries to adopt others for the purpose of solving the 'relevance' problem [3]. Therefore, they have to concede that they cannot explain complexities in terms of current management research paradigms.

The second problem is a probability that the management theory does not 'want' to closely link with business practices. In reality, the rationale of management science is questioned and critiqued. To maintain management theories reputations and prestige, management scientists try to consolidate its industry characteristics and raise its barriers. Tourish (2019, p. 7) [10] concluded that many problems related to management research originate from the outset of the discipline, which includes 'a political agenda that obscures issues of power and so serves dominant interests', and 'poorly designed studies' that employ an assumption that theories generated by a small sample to a big population that consists of everyone who has a job in the world. In simple words, the management research propelled by political interests (i.e., exploiting labour forces by so-called management science) is critiqued by its axiology stance. He puts the example of Taylor and illustrates how Taylor is critiqued both as a revered and appalling figure as a management scientist.

In addition, the research on management is centric at the studies of 'people', and since the 1950s, the hypotheses of human nature shifted five times in western management theories, including 'Tool man', 'economic man', 'social man', 'ethic man', and 'innovation man' [14]. Though in a different era, the labour force has been regarded as different 'objects' to study, it 
is arguable whether these propositions should be adopted as true hypotheses for management studies as a 'science' [14-16]. Given the research objects are 'people', it is very difficult to continually push the advances of 'productivities' by unethically exploiting 'people'. Therefore, this is why management scientists are reluctant to study some sensitive people productivities issues.

In terms of research design, management scientists attempted to utilise the research paradigm to solve the real practice problems while these theories methodological designs do not apply to a wider extent, which causes the tensions between business practitioners and academy practitioners. Chen concerned the rigorous thinking and studies in the management discipline and expressed that 'the rise of big data and artificial intelligence, the Mechanistic Materialism overemphasised the information, data, and mechanic information processing system, which leads to inflexible and rigid research paradigms that cannot insightfully interpret unstable and everchanging management practices, and cannot solve real and flexible management problems' [8]. For instance, scholars just copy modes from economics and finance, and quantitatively analyse and discuss data (interpreting phenomena into constructs and then numerical data), and heavily rely on software such as SPSS, EMOS, Stata, to explain implicit phenomena such as innovations, office politics, and employee engagement.

Lv (2011) [17] concluded that regarding China management study paradigm, it mainly encounters three problems from business relevant perspectives: (a) focusing on tools and measures of management instead of studying ontology; (b) highlighting management science instead of the art of management, for example, mainstream publications and other management academic studies and education neglect the publications and studies of the art of management, however, in practice, the art of management is significantly important. In fact, management is not only a science but also an art. Tylor contends that 'management is the art of knowing what you want to do and then seeing that they do it in the cheapest and the best way.'; and (c) often adopting empirical studies. Empirical studies take advantages to test and correspond theories development; however, it fails to explain those intangible and unexplained situations. Professor Xie Yong Zhen questioned whether empirical studies should be regarded as the measures to hypothetically test management theories and she claimed that many management theories are impossible to empirically falsify, but they are found to be useful and beneficial in real practice [8].

Measures and means of management are confined to multiple conditions, affected by the economy, politics, culture, and other external and holistic factors. In contrast, the effects between theoretical modes and real practices are drastically varied when there are minor disparities. Hence, if management researchers turn blind to those implicit and intangible facts and use a rigid and so-call 'scientific' paradigm to solve management issues, it deliberately overlooks the 'relevance' of management studies but produces 'sound' results [6,9].

To conclude, management scientists may both have problems in developing theories due to rapid change environment and problems in academic studies towards real management practice because of sensitive ethical issues, abandoning research paradigm, turning into research management 'art' instead of 'science', and so forth.

\section{Rigour and relevance, it is hard to balance}

In a paper, for a Special Issue: Journal Rankings and the Notion of 'Relevance' within Business Research from European Business Review, Narasimhan (2018) [18] examines both ends of rigour and relevance, and he argues that 'Rigour without relevance is an intellectual exercise that an applied field such as ours can ill afford to persist in. Relevance without rigour renders the research less valuable due to the uncertainty surrounding the validity of the proposed ideas.'

The debate of rigour and relevance lasts many years, and scientists are struggling to balance two ends, especially facing mounting pressures on 'publish or perish'. Narasimhan (2018) [18] asserts that some papers may be highly relevant if they adopt theories or frameworks to process a large amount of data or to create new theoretical frameworks, but these publications should be classified rigorous instead of relevant, as they possess little practical significance. He creates a $2 \times 2$ matrix to explain the classification of rigour and relevance of the paper (see Table 1).

In this matrix, both ends had its implications to readers, but he argued that the simultaneity of rigour and relevance is possible [18]. However, what business schools have produced is irrelevant to industry needs and 'business school scholarship can be a massive diversion of resources in ways that benefit faculty, not society' [19]. The impact of an article needs to be evaluated from both rigour and relevance ends, but not exclusively based on whether its publication on a 'top-tier' journal. According to Lambert (2019) [3] argued, without relevance, 
Table $12 \times 2$ Matrix of rigour and relevance

\begin{tabular}{llll}
\hline & & \multicolumn{2}{c}{ Rigour } \\
\cline { 3 - 4 } & High & Seminal articles, high Impact, published in academic journals & Lotentially rich insight of practical importance in some readings \\
Relevance & Low & Academic interests, published in the top-tier journal & $\begin{array}{l}\text { Published for academic degree requirements or other authors' needs } \\
\text { that irrelevant from both academic and practical implications }\end{array}$ \\
\hline
\end{tabular}

Source: Narasimhan (2018) adapted by the authors [18]

academic management research will cease to be of practical importance. Actually, without practice implications, academic research is more than a pie in the sky.

Scholars found that from relevance perspective, many problems are related to business management research. After discussions with several executives from leading companies, such as IBM, Hewlett Packard, Schneider and Siemens, Storbacka (2014) [20] found that managers believe academic studies 'simplify matters beyond managerial relevance' and 'academics are interested in doing research on issues that managers consider were solved many years ago.' Stentoft (2017) [21], consistent with Storbacka (2014) [20], claimed that the research towards theories is not beneficial for management practitioners, as those basic and common problems are already solved. Obsessive investment into those irrelevant theories is wiseacre, as it goes to waste public funds and creates nonsenses from the relevance end [22].

The chief editor of an elite Chinese business journal Nankai Business Review, Bai (2020) [6], found that when reviewing manuscripts for publication, four salient problems of academic papers are found in terms of relevance. First, the hypothetic modelling is distant from a business application, which damages the value of the application. Second, the constructs adopted by some authors are oversimple, which is labour saving but impairs the observations and clarity of phenomena. Third, among some case studies and qualitative studies, the observations to real cases are not detailed and sufficient, contributed to the scarcity of evidence details and undermined theory-building foundations. In this sense, the theory constructed is drifted away from practices. The last is that most academic papers attempt to compile abundant literature reviews in the academic studies despite of the relevance of literature.

In the crossroad of relevance and theory development, researchers may do not want to 'pertain' their studies with problems in management practices, because this would not be awarded and accepted by academia and elite journals. Scholars are presumably 'lazy' to study real problems in practice but just closely follow the academic paradigms to solve 'relevant problems' that 'might' have implications to the industry. The attempts made in theoretical development are effective to themselves in terms of academic degree promotion and salary increment, but, it is of little effect to management practitioners as it does not 'deliver practical value in a specific context' and 'there are numerous works... that utilize stylized models and execute known mathematical procedures flawlessly to develop "insights" that have little or no practical significance [18].'

According to CEEMAN Manifesto (The Central and East European Management Development Association), in terms of a management research realm, much interest has been drawn on research and publication instead of teaching; prefers quantitative research to qualitative studies; methodological precision over pertinent substance; theories over practices; and highlights the recognition of peer than business practices [23]. The noteworthy phenomenon is that an increasing number of quantitative research has become popular among scholars who excel at these techniques in their own research fields [24].

Aforementioned, the management study has its limitation as a science. Not until the later $20^{\text {th }}$ century, it became a subject that adopts the quantitative research method to promote its ideology and improve its reliability and trustworthiness [25]. Unlike nature science or formal science (e.g. mathematics), management science as the applied science or social science is lack 'scientific' spirits [26], because it studies the implicit and uncontrollable variables. Therefore, welcome is the quantitative research which adds variables and complicated formula and functions that turns the management research into rigorous and scientific research [25]. Latham $(2014$, p. 12) [12] argued that to generalise theories, the adoption of 'positivist and post-positivist methods with quantitative measurement and probability samples' is a desire of researchers who claim to be real scientific research in many social science disciplines like what other physical scientists do. However, it does not simply claim that using quantitative research paradigm can solve implicit and ambiguous management issues scientifically.

However, it is not attributed wholly to the researchers, because pursuing ' $A$ ' journals is an urgent need for schools and other stakeholders as well. As an important indicator, business schools often regard the publications of teachers or searchers as a tool of performance management. Lambert (2019) [3] asserts that the business schools attempt to improve their rankings 
by publishing more articles in highly ranked journals, which leads to a biased performance management system, that is, pays too much attention to faculty productivity with a quantitative metric, but neglects real effects and contributions towards business community. McKinnon (2013) [4] concluded that the ranking of journals became influential in management as the institutions often regarded the journal ranking as a proxy to manage the performance of researchers and professors. In recognition of this, more researchers pursue publications in leading or important journals. In practice, to raise ranking, business schools employ those fruitful researchers for publications by assigning them little work in teaching with generous pay, while recruiting part-time and cheap labour force for teaching as much as possible [27]. Therefore, this performance and reward management mode inspire researchers to publish those 'nonsense' in practice but look good on paper. Therefore, what schools need to do is, as Lambert (2019) [3] concluded, that the imperative of writing and research is out of the author's interests instead of other indexes.

What is more? Editors of top journals are interested in those publications which are dedicated to vertical theory-building instead of horizontal practice exist; thus, this preference drives the scholars in business school to pursue the publication in ' $\mathrm{A}$ ' journals from an academic perspective solely [28]. The background of editors has been a concern. It is found that the decreasing number or missing editors from business or industry background for three leading journals including International Journal of Logistics Management; International Journal of Physical Distribution and Logistics Management; and Journal of Business Logistics since last four decades [28]. More academic professors in editor positions lead to the changing appetites of journals from practices to theories, which, to a large extent, demotivates manuscripts submitted for business problems solutions and increases the likeliness of rejection.

In addition, elite journals are selected to languages in publication. From a wording perspective, as Grey and Sinclair (2006) [29] argued, in the business research field, much of the writing is 'jargon-ridden, laboured'. They contended that serious academic writing and an equally abstracted vocabulary decorates studies in a scientific and serious manner, contributing to scholars' qualifications. In this sense, management scientists voluntarily demotivate readers from those management practitioners from what they have been published. Billig (2013) [30] argued that management scholars have to use those big words and languages 'not to identify a discovery, but to cover over a lack of discovery' and in this strategy, they can survive from a competitive research society.

Language norms used in academic writing is contrary to what perceived valuable insights and those sparking implications, and disciplined imaginations are lapsed because of insufficient writing formats [25]. Though to either scholars or editors, to use these rigid and 'scientific' words may benefit the publications and acknowledgement from peers and academicians, but it derails from the 'relevance' track of management practices. For example, using big words and rigorous and picky terms possibly demotivates those management practitioners to digest those research results, as what Tourish $(2019$, p. 7) [10] claimed that 'the world faces major challenges across numerous issues. Many of these are organisational $\cdots$ it is my belief that management scholars can make important contributions to these issues. At present, we generally do not. Most managers don't read our research and most of the public is unaware that it even exists.'

Overall, management scientists are both internally and externally pushed to publish more theory-like papers than relevance papers. Their rigourous publications could be awarded extendedly academically and financially. Their employers, such as business schools, can have reputations in academia and recruit more students easily. The top-tier journals can be beneficial for those rigourous theory development papers because of more citations, which helps them to consolidate their ranking. Thus, these factors contribute to more publications from rigour end.

\section{Self-plagiarism, a debated 'self-plagiarism' technique to produce papers}

To prevent academic misconduct, in 2019, the Academic publishing specification-Definition of academic misconduct of journals (hereafter short for Specification), has been authorised and released by China National Press and Publication Administration [31]. The Specification defined academic misconducts come from various stakeholders including authors, reviewers, and editors. The regulation is the comprehensive, inclusive, standard, and detailed. Li Zhen Zhen, a researcher in Technology and Strategy Consulting Institute of China Academy of Science, commented that 'this is a first national standard of academic misconducts of China and it also provides a series of definitions to specific academic misconducts, including plagiarism, inappropriate authorship, falsification, fabrication, multiple submission, and overlapping publication, 
which is beneficial for defining and assessing academic misconducts in real practices' [32].

Along with the Specification, two main official documents for the purpose of the prevention of academic misconducts in research fields are enacted by the Ministry of Education of the People's Republic of China including Measures for the Handling of Acts to Falsify Dissertations [33] and The Measures for the Prevention and Punishment of Academic Misconducts in Institutions of Higher Education [34]. These effective measures are proposed to solve academic misconduct in higher education institutions. Together, three regulations give implications in academic governance dealing with academic ethical issues.

However, per Li Zhen Zhen, some debated ethical issues, such as Segmented Publication which is also known as salami-slicing, have not been tackled with [32]. The segmented publication refers to an integral research paper that has been detached into several papers to publish in order for more publications, and it has been done by restructuring the topic, data, materials, and existing structures [35]. According to Committee on Publication Ethics (COPE), segmented publication occurs when researchers publish one experiment on two or more papers which prevents the readers from gaining more information on a single paper [36]. In fact, the segmented publication is a form of 'self-plagiarism', though writers prefer to call i 'text re-use' [37].

In the face of external pressures to academic publications, scholars have to publish the more papers on high-ranking journals. Due to heavy punishment towards copyrights infringements, scholars are aware of threats from copying and paste others' work intentionally, but the slicing publication is categorised into grey areas, whereas many researchers may use their existing publications as many as possible to expand their influences on the scientific field. Indeed, heated debate is raised, but in China, it is widely accepted by scholars that using their own properties is legitimate and legal [39]. Problems caused by 'Segmented Publication' have been underestimated by many researchers because they argue this kind of activity is 'for the purpose of spreading own knowledge and ideas to reach wider masses' [37]. Researchers may claim their copyright and use of existing research results, but they may neglect the repetitive publications and wastes the time of readers.

Zhang (2020) [38] argued that, though many ethnic associations and scholars have been discussing the segmented publications, it is a lack of assessment and impetus to evaluate salami publication. He pointed out that difficulties of identifying the segmented publication are evident, though publishers and peer reviewers try their best to discern the segmented publications by examining paper content, data reliability and trustworthiness, experiments process, the integrity of the paper, and so forth, it still needs the improvement of awareness from academic practitioners, and improved publications system, and academic ethical building of Academia.

Segmented Publication is an issue that misleads the judgement of research ethics. Researchers may argue that it would be regarded as minor errors when referring to Segmented Publication among the academic community as if this kind of self-plagiarism is not viewed as a condemnable act $[36,40,41]$. Though researchers decline to 'steal themselves', it is a possible way to deceive readers by repetitive and similar papers whereas can be considered as intellectual laziness [41].

Segmented Publication can pose threats to audience and other stakeholders. This kind of 'self-plagiarism' could lead to the waste of time because peer-reviewers may find that it is useless to review identical and published data which wastes their time [42]. Readers may feel be cheated as they may be familiar with previous data and methods when they expect to have new ones, so if authors reuse their previous texts and data without good citation, it leads to the waste time of readers to go over the whole sections again [43]. Those clean and integrous researchers may lose their opportunities to compete as their 'pale' resume with seldom publications compared to those 'productive self-plagiarism' scientists [37]. In some cases, serious self-plagiarism may result in copyright infringement without explicit permission from the publisher such as reuse of texts, figures, and other materials; and the manuscripts may be retracted from publishers after publications because thousands of readers will continually check the manuscripts after publications [42].

\section{Conclusion}

Management theory development is not always smooth, but many scholars worked hard to contribute to this development which is beneficial for our social development as a whole. However, due to various reasons, though many management students strive to be integrous, unblemished management scholars, it seems hard to pursue virtuous paragon. fact, some factors may hurt young scholars' impetus of being ethical scientists, while others may hinder the development and sustainability of our management studies in the long run.

This paper firstly discussed the detail of relevance and theoretical development and asserted 
that our management theories may not be able to explain management practices, and our management scientists may 'intentionally' not to connect their studies with practices. Secondly, it went to discuss conflicts between rigour and relevance. We summarised that redundant research on useless theory, preferences of quantitative methods, desires for pursuing elite journals, pressures of academic performance appraisal, and requirements from top tire journals are some reasons why management scientists overvalued rigour to relevance. Lastly, we found that, though authorities enact various legislations and regulations, some 'self-plagiarism' behaviours, such as 'segmentation publication', are still debatable and prevalent, and we are still on the way to solve them.

Given this scenario, how do we address these problems is a vital problem not only for elite researchers and journals but also for every scholar and student in the management academy This paper argues that necessities are the change of the rating system for the management and business scholars; the balance between theory development and practice-related studies; and the decrease of repetitive publications by raising authors' self-awareness.

\section{References}

[1] Martinson BC, Anderson MS and De Vries R. Scientists behaving badly. Nature, 2005, 435(7043): 737-738. https://doi.org/10.1038/435737a

[2] Martinson BC, Anderson MS, Crain AL, et al. Scientists' perceptions of organizational justice and self-reported misbehaviors. Journal of Empirical Research on Human Research Ethics, 2006, 1(1) 51-66. https://doi.org/10.1525/jer.2006.1.1.51

[3] Lambert DM. Rediscovering relevance. The International Journal of Logistics Management, 2019, 30(2): 382-394. https://doi.org/10.1108/IJLM-02-2019-0059

[4] McKinnon AC. Starry-eyed: journal rankings and the future of logistics research. International Journal of Physical Distribution \& Logistics Management, 2013, 43(1): 6-17. https://doi.org/10.1108/09600031311293228

[5] Liu SB. Embarrassment of management study, 2019. https://www.huxiu.com/article/317877.html

[6] Bai CH. Research studies redirecting practice oriented. Nankai Business Review, 2020, 23(2): 2-3. https://doi.org/10.31193/SSAP.J.ISSN.2096-6695.2020.01.01

[7] Qi SH, Bai C, Chen C, et al. The Forecast: Facing the Chinese Management Practice. China Journal of Management, 2010, 7(11): 1685-1691.

[8] Jia XD and Kong ZX. Interactive innovation of Chinese Management Research and Practice: Review and Outlooks from the 10th Forum of "China-Practice-Management". China Journal of Management, 2020, 17(3): 338-343.

[9] Qi SH. Rethinking the core management proposition from practice perspective. China Journal of Management, 2012, 9(1): 32-37.

[10] Tourish D. Management studies in crisis: Fraud, deception and meaningless research: Cambridge University Press, 2019. https://doi.org/10.1017/9781108616669

[11] Bennis W. Leadership in a digital world: embracing transparency and adaptive capacity. Management Information Systems Quarterly, 2013, 37(2): 635-636.

[12] Latham J. Leadership for quality and innovation: Challenges, theories, and a framework for future research. Quality Management Journal, 2014, 21(1): 11-15. https://doi.org/10.1080/10686967.2014.11918372

[13] Torres R and Reeves M. Adaptive leadership. Leadership Excellence, 2014, 28(7): 8.

[14] Zhu JH and Fan Y. Research on the Historical Changes and Development Trend of "Human Nature Hypothesis" - Based on Critical Analysis of Western Management Theory. Economic Research Guide, 2010, 33: 211-212.

[15] Hu S and Kang TG. Evaluation of Western Human Nature Supposition Theory and Related Management Model. Commercial Science Research, 2008, 3: 43-45.

[16] Renqing D. The Reasonable Essence and Enlightenmen of the Theory of Human Nature Supposition about West Psychology of Management. Journal of Qinghai Normal University (Philosophy and Social Sciences), 2008, 131(6): 142-145.

[17] Lv L. Meta-Issues of Management and Management Philosophy :Discussion on Logic Defect of'The Forecast:Facing the Chinese Management Practice'. China Journal of Management, 2011, 8(4): 517-523.

[18] Narasimhan R. The fallacy of impact without relevance - reclaiming relevance and rigor. European Business Review, 2018, 30(2): 157-168. https://doi.org/10.1108/EBR-01-2017-0005

[19] Glick W, Tsui A and Davis G. The moral dilemma of business research, 2018. https://bized.aacsb.edu/articles/2018/05/the-moral-dilemma-of-business-research 
[20] Storbacka K. Does publish or perish lead to stylish rubbish? Journal of Business Market Management, 2014, 7(1): 289-295.

https://doi.org/10.1007/978-3-319-03976-3_1

[21] Stentoft J. Practitioners Perspectives on Contemporary Supply Chain Management Issues: The Danish Supply Chain Panel 2012-2016. University Press of Southern Denmark, Odense: Syddansk Universitetsforlag, 2017.

[22] Stentoft J and Freytag PV. Guest editorial. European Business Review, 2018, 30(2): 94-100. https://doi.org/10.1108/EBR-11-2017-0217

[23] CEEMAN. Changing the Course of Management Development: Combining Excellence with Relevance, 2018) http://www.ceeman.org/docs/default-source/publications/ceeman-manifesto.pdf

[24] Podolny JM. The buck stops (and starts) at business school. Harvard Business Review, 2009, 87(6): 62-67.

[25] Tourish D. The triumph of nonsense in management studies. Academy of Management Learning Education, 2020, 19(1): 99-109. https://doi.org/10.5465/amle.2019.0255

[26] McEwen M and Wills EM. Theoretical basis for nursing: Lippincott Williams \& Wilkins, 2017.

[27] Alvesson M. The triumph of emptiness: Consumption, higher education, and work organization: OUP Oxford, 2013 https://doi.org/10.1093/oso/9780199660940.001.0001

[28] Lambert DM and Enz MG. We must find the courage to change. Journal of Business Logistics, 2015, 36(1): 9-17. https://doi.org/10.1111/jbl.12078

[29] Grey C and Sinclair A. Writing differently. Management Learning, 2006, 13(3): 443-453. https://doi.org/10.1177/1350508406063492

[30] Billig M. Learn to write badly: How to succeed in the social sciences. UK: Cambridge: Cambridge University Press, 2013. https://doi.org/10.1017/CBO9781139208833

[31] NPPA. Academic publishing specification - Definition of academic misconduct of journals, 2019. https://bmi.sjtu.edu.cn/class_slides/ethics.pdf

[32] Gao LY. Misconducts in Journals 'legislated' China Science Newspaper, 2019. http://news.sciencenet.cn/sbhtmlnews/2019/7/347901.shtm

[33] MEPRC. Measures for the Handling of Acts to Falsify Dissertations, 2012. http://www.moe.gov.cn/srcsite/A02/s5911/moe_621/201211/t20121113_170437.html

[34] LawinfoChina. Measures for the Prevention and Punishment of Academic Misconducts in Institutions of Higher Education, 2016. http://www.lawinfochina.com/display.aspx?id=22986\&lib=law

[35] Zhang N. Academic misconducts in postgraduates research. (Master), Shihezi University, Shihezi, 2014. https://cdmd.cnki.com.cn/Article/CDMD-10759-1015512570.htm

[36] Arumugam A and Aldhafiri FK. A researcher's ethical dilemma: Is self-plagiarism a condemnable practice or not? Physiotherapy Theory and Practice, 2016, 32(6): 427-429. https://doi.org/10.1080/09593985.2016.1185894

[37] Schneider L. Self-Plagiarism: helps careers, hurts noone? 2016. https://forbetterscience.com/2016/07/04/self-plagiarism-helps-careers-hurts-noone

[38] Zhang M. Academic Thesis Redundant Publication Behaviours Analysis and Preventive Measures. Science-Technology and Publication, 2020, 39(8): 82-86.

[39] Qiu WT. On "Self-plagiarism” Journal Of Ningbo Radio \& TV University, 2018, 18(13): 2.

[40] Eaton SE and Crossman K. Self-Plagiarism Research Literature in the Social Sciences: A Scoping Review. Interchange, 2018, 49(3): 285-311. https://doi.org/10.1007/s10780-018-9333-6

[41] Lancet. Self-plagiarism: unintentional, harmless, or fraud? The Lancet, 2009, 374(9691): 664. https://doi.org/10.1016/S0140-6736(09)61536-1

[42] Bonnell DA, Buriak JM, Hafner JH, et al. Recycling Is Not Always Good: The Dangers of SelfPlagiarism. ACS Nano, 2012, 6(1): 1-4. https://doi.org/10.1021/nn3000912

[43] Schneider L. Academic self-plagiarism: misconduct or a literary art form? 2016. https://forbetterscience.com/2016/04/11/academic-self-plagiarism-misconduct-or-a-literary-art-form 